\title{
Lifestyle factors and breast cancer in a Moroccan population case-control study of the center Mohammed VI for cancer treatment
}

\author{
Drissi Houda $^{1 *}$, Imad Fatima Ezzahra ${ }^{1}$, Bendahhou Karima ${ }^{2}$, Benider Abdelatif ${ }^{3}$, \\ Radallah Driss ${ }^{1}$
}

\author{
${ }^{1}$ Laboratory of Biology and Health, Associated Research Unit CNRST, URAC-34, Faculty of Sciences Ben M'sik \\ University Hassan II of Casablanca, Morocco \\ ${ }^{2}$ Cancer registry of the Greater Casablanca, Morocco \\ ${ }^{3}$ Center Mohammed VI for the Treatment of Cancers, Casablanca, Morocco
}

Received: 07 August 2019

Accepted: 07 September 2019

\author{
*Correspondence: \\ Dr. Houda Drissi, \\ E-mail: houda.drissi04@gmail.com
}

Copyright: () the author(s), publisher and licensee Medip Academy. This is an open-access article distributed under the terms of the Creative Commons Attribution Non-Commercial License, which permits unrestricted non-commercial use, distribution, and reproduction in any medium, provided the original work is properly cited.

\begin{abstract}
Background: The study aims to examine the association between lifestyle habits and breast cancer risk in a Moroccan population.

Methods: This is a case-control study conducted at the Mohammed VI Centre for cancer treatment in Casablanca.

Results: The results highlighted that family history of breast cancer $(\mathrm{OR}=5.73)$ and alcohol consumption $(\mathrm{OR}=3.76)$ were positively associated with breast cancer. Analysis of anthropometric parameters showed that the risk of developing breast cancer is estimated at 1.78 in overweight women and 2.39 in obese women compared to those of normal weight. The risk of developing breast cancer is estimated at 1.82 for women with a WC greater than $88 \mathrm{~cm}$ and 1.70 for women with a WHR greater than 0.85. At age 10, the risk is 1.60 for women with a large figure compared to women with a small figure. However, at age 40, the average body shape relative to the lean body was associated with a decreased risk of breast cancer. In addition, the data confirmed that physical activity participation decreases with age; in childhood and adolescence, women are more active while in post-menopause, women become moderately active. Being very active in childhood, peri-menopause and post-menopause seems to be a protective factor against the occurrence of breast cancer.

Conclusions: The study showed that the risk of breast cancer is potentially high in elderly women, overweight women and women with a family history of cancer. This risk was increased by behavioral factors such as toxic habits and physical inactivity.
\end{abstract}

Keywords: Anthropometric measurements, Breast cancer, Case-control study, Physical activity, Toxic habits

\section{INTRODUCTION}

Breast cancer is the most common cancer in the female population. The main factors predicting breast cancer risk in women have been identified as: age, family history and genetic factors such as mutations in the BRCA1 and BRCA2 genes and other high-penetrance genes, such as the p53 gene. ${ }^{1,2}$ Over the past two decades, many surveys have examined the possible role of lifestyle factors, such as smoking and alcohol consumption, in increasing the risk of breast cancer. ${ }^{3-5}$ According to Nkondjock and Stasiołek, physical inactivity and obesity are among the risk factors for this cancer. ${ }^{6,7}$ Some of these behavioural risk factors can be easily modified, so their modification 
can play an important role in breast cancer prevention. ${ }^{8}$ The study aimed to evaluate breast cancer risk factors related to patients' lifestyle habits such as weight gain, smoking status, alcohol consumption, physical inactivity, among a Moroccan population in the Greater Casablanca region.

\section{METHODS}

This is a case control study conducted at the Mohammed VI Centre in Casablanca for cancer treatment.

Participants are asked for prior informed consent to participate in the study. Explanations are given about the interest of the study, in compliance with the rules of the National Commission for the Control of Personal Data Protection. The newly diagnosed breast cancer patients at the centre were included in the study from January 2015 to December 2016. Controls free of all cancer diseases were included among the patients admitted to the dermatology and ophthalmology consultations at the Ibn Rochd University Hospital in Casablanca. Patients and controls were matched by age.

Data collection was done prospectively using a standardized, face-to-face questionnaire administered to patients. Data were collected on age at diagnosis, menopausal status, family history of cancer, and toxic habits (smoking status and alcohol consumption).

\section{Anthropometric parameters}

Anthropometric parameters, patient weight and height were measured and the body mass index was calculated according to the formula

$\mathrm{BMI}=$ weight $(\mathrm{kg}) /$ height $(\mathrm{m})^{2}$

The data are analyzed and compared to the World Health Organization (WHO) classification $\left[<25 \mathrm{~kg} / \mathrm{m}^{2}\right.$ (normal weight), $25-30 \mathrm{~kg} / \mathrm{m}^{2}$ (overweight), $>30 \mathrm{~kg} / \mathrm{m}^{2}$ (obese)].

Waist and hip circumference, rounded to the nearest centimetre, were also collected and the waist and hip circumference ratio WHR [Waist circumference $(\mathrm{cm}) / \mathrm{hip}$ circumference $(\mathrm{cm})]$ was calculated. Waist circumference is the simplest criterion for assessing abdominal fat, which is directly implicated in breast cancer.

\section{Evolution of corpulence over the life course}

For corpulence at different ages (between childhood and inclusion in the study), we used the female silhouettes on the Sorensen scale (Figure 1 as an indicator). ${ }^{9}$ Women were asked to choose from eight silhouette drawings (numbered from 1 to 8 , from the smallest to the largest) those that most closely resembled their silhouette at age $10,20,30$ and 40 .
From these eight silhouettes and in order to have enough subjects in each category for statistical analysis, groupings were made. At the age of 10, the "lean" category corresponds to figure 1 , the "medium" category corresponds to Figure 2 and the "tall" category corresponds to figures 3 to 8 . As for body size between 20 and 40 years of age, the "lean" category corresponds to silhouettes 1 and 2 , the "medium" category corresponds to silhouette 3 and the "tall" category corresponds to silhouettes greater than or equal to 4 .

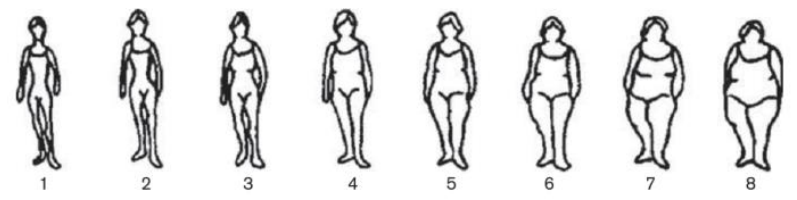

Figure 1: Sorenson silhouettes to assess body shape at different ages.

However, this study has some limitations. The evaluation of body shape at different ages, using Sorensen shapes, requires long-term memory, which can lead to measurement errors. However, numerous studies showed that this information was reliable as an indirect indicator of the body's actual shape. ${ }^{11,12}$

\section{Physical activity}

Data on physical activity were also collected. They cover activities related to professional tasks, walking and/or vigorous or moderate sporting activity

\section{Statistical analysis}

A univariate analysis was conducted to identify factors associated with breast cancer. For this analysis, we used conditional logistic regression because it is a case-control study where age matching was done (one control for one case). The statistical analysis was done using the $\mathrm{R}$ software. The risk calculation quantifying the exposure/disease association was done by Odds Ratio (OR) and $95 \%$ confidence intervals $(95 \% \mathrm{CI})$. The significance threshold has been set at $5 \%$.

\section{RESULTS}

During the study period, a total of 305 patients presenting for breast cancer managed at the Mohammed VI Centre for Cancer Treatment and 305 controls free of any cancer disease were included. Cases and controls are agematched.

\section{Age, menopausal status and family history of cancer}

The results obtained on associations between age, menopausal status, family history of cancer and breast cancer risk between cases and controls are shown in Table 1. The average age of all patients is 50.43 years, with a standard deviation of 11.21 years with extremes 
ranging from 23 to 95 years. Regarding menopausal status, our results show that $56.1 \%$ of patients are menopausal vs. $55.4 \%$ of controls. No association was found between menopausal status and breast cancer risk $(\mathrm{OR}=1.05 ; 95 \% \mathrm{CI}: 0.75-1.47$; $\mathrm{P}$ trend $=0.56)$.

Family history of breast cancer was present in $20.33 \%$ of cases versus $4.26 \%$ of controls. Thus, the risk of developing breast cancer is estimated at 5.73 in women with a family history of breast cancer compared to those without $(\mathrm{OR}=5.73 ; 95 \% \mathrm{CI}: 3.07-10.67 ; \mathrm{P}$ trend $=$ $0.0001)$. As for the family history of other types of cancers, they were present in $25.57 \%$ of cases versus $9.2 \%$ of controls. The risk of developing breast cancer is estimated at 3.39 in women with a family history of other types of cancer compared to those without $(\mathrm{OR}=3.39$; 95\% CI: 2.13-5.41; P trend $=0.0001$ ).

\section{Toxic habits}

The results obtained on the associations between patients' toxic habits and breast cancer risk between cases and controls are shown in Table 2. The majority of patients in the study population (93.4\%) were non-smokers versus $96 \%$ of controls, only a few patients reported being exsmokers or smokers, with $4.3 \%$ and $2.3 \%$ respectively in cases versus $2 \%$ ex-smokers and $2 \%$ smokers in controls, or $\mathrm{OR}=1.19 ; 95 \% \mathrm{CI}: 0.39-3.61 ; \mathrm{P}$ trend $=0.1$. In addition, only 18 cases investigated $(5.9 \%)$ reported alcohol consumption versus 5 cases (1.6\%) among controls. Thus, the risk of developing breast cancer is estimated at 3.76 for women who drink alcohol compared to those who do not $(\mathrm{OR}=3.76 ; 95 \% \mathrm{CI}: 1.37-10.26 ; \mathrm{P}$ trend $=0.0001$ ).

\section{Anthropometric measurements}

The results regarding the association between anthropometric measurements in women with breast cancer compared to controls are presented in Table 3 . The patients in our study measured an average of $1.62 \mathrm{~m}$, $76.42 \mathrm{~kg}$ and an average BMI of 29.06. In contrast, female controls averaged $1.62 \mathrm{~m}$ in height, $72.69 \mathrm{~kg}$ and a BMI of 27.53, with a significant difference $(\mathrm{p}=0.0001)$. There was no significant difference between cases and controls in size.

The BMI analysis found that $39 \%$ of cases were overweight compared to 35.7 in controls and $37.3 \%$ obese compared to 25.6 in controls. The risk of developing breast cancer is estimated at 1.78 in overweight women and 2.39 in obese women compared to those of normal weight $(\mathrm{OR}=1.78 ; 95 \% \mathrm{CI}$ : 1.20 2.64; $\mathrm{P}$ trend $=0.0001)$ and $(\mathrm{OR}=2.39 ; 95 \% \mathrm{CI} 1.58-$ 3.61 ; $\mathrm{P}$ trend $=0.0001$ ). For waist circumference $(\mathrm{WC})$ distribution, our results show that $78.7 \%$ of patients have a WC greater than $88 \mathrm{~cm}$ versus $68.5 \%$ of controls. As for the waist-to-hip ratio (WHR), $65.6 \%$ of cases have a WHR greater than 0.85 versus $52.8 \%$ of controls. The risk of developing breast cancer is estimated at 1.82 in women with a TT greater than $88 \mathrm{~cm}$ and 1.70 in women with a WHR greater than $0.85(\mathrm{OR}=1.82 ; 95 \% \mathrm{CI}: 1.09$ - 3.06; $\mathrm{P}$ trend $=0.02)$ and $(\mathrm{OR}=1.70 ; 95 \% \mathrm{CI}: 1.20$ 2.36; $\mathrm{P}$ trend $=0.001$ ).

\section{Evolution of corpulence over the life course}

The other objective of the work was to study the influence of the evolution of corpulence over the life course (from childhood to adulthood) on the occurrence of breast cancer in patients compared to controls. Most women chose silhouettes 1 and 2 to describe their body shape at age 10 (50\% in breast cancer cases and 40\% in controls; Figure 2). These proportions decrease drastically at age 20 (17.4\% and $20 \%$, respectively), to be almost nil at age 40. At age 10, Figure 2 is the most reported with $30.2 \%$ in cases versus $25.9 \%$ in controls with $(p=0.03)$. At the age of 20 years, silhouette 4 is the most frequent with $33.1 \%$ in patients compared to $28.9 \%$ in controls with an insignificant $\mathrm{p}(\mathrm{p}=0.15)$. At 40 years of age, figure 6 is the most frequently chosen with $27.3 \%$ in cases vs. $23.3 \%$ in controls $(p=0.002)$, Figures 7 and 8 were also reported by $15 \%$ of patients and only $9 \%$ of controls. Results regarding the association between lifetime body image perceptions in women with breast cancer compared to controls are presented in Table 4.

Table 1: Associations between menopausal status, family history and breast cancer risk between cases and controls.

\begin{tabular}{|c|c|c|c|c|c|}
\hline Features and characteristics & Cases $(\%) \mathrm{N}=305$ & Control (\%) $\mathrm{N}=305$ & OR & $95 \% \mathrm{CI}$ & P trend \\
\hline Age & $50.43 \pm 11.21$ & & & & \\
\hline \multicolumn{6}{|l|}{ Menopausal status } \\
\hline Pre-menopause & $114(37.4)$ & $119(39)$ & & 1 & \multirow[t]{3}{*}{0.56} \\
\hline Peri-menopause & $20(6.6)$ & $17(5.6)$ & 1.22 & $0.61-2.46$ & \\
\hline Post-menopause & $171(56.1)$ & $169(55.4)$ & 1.05 & $0.75-1.47$ & \\
\hline \multicolumn{6}{|l|}{ Family history of breast cancer } \\
\hline No & $243(79.7)$ & $292(95.7)$ & & 1 & \multirow[t]{2}{*}{0.0001} \\
\hline Yes & $62(20.3)$ & $13(4.3)$ & 5.73 & $3.07-10.67$ & \\
\hline \multicolumn{5}{|c|}{ Family history of other types of cancer } & \multirow[t]{3}{*}{0.0001} \\
\hline No & $227(74.4)$ & $277(90.8)$ & & 1 & \\
\hline Yes & $78(25.6)$ & $28(9.2)$ & 3.39 & $2.13-5.41$ & \\
\hline
\end{tabular}


Table 2: Associations between toxic habits and breast cancer risk between cases and controls.

\begin{tabular}{|c|c|c|c|c|c|}
\hline Features and characteristics & Cases $(\%) \mathrm{N}=305$ & Control (\%) $\mathbf{N}=305$ & OR & $95 \% \mathrm{CI}$ & P trend \\
\hline \multicolumn{5}{|l|}{ Smoking status } & \multirow{4}{*}{0.1} \\
\hline Non-smoker & $285(93.4)$ & $293(96)$ & & 1 & \\
\hline Smoker & $7(2.3)$ & $6(2)$ & 1.19 & $0.39-3.61$ & \\
\hline Ex-smoker & $13(4.3)$ & $6(2)$ & 2.22 & $0.83-5.94$ & \\
\hline \multicolumn{5}{|l|}{ Alcohol consumer } & \multirow{3}{*}{0.01} \\
\hline No & $287(94.1)$ & $300(98.4)$ & & 1 & \\
\hline Yes & $18(5.9)$ & $5(1.6)$ & 3.76 & $1.37-10.26$ & \\
\hline
\end{tabular}

Table 3: Associations between anthropometric measurements and breast cancer risk between cases and controls.

\begin{tabular}{|c|c|c|c|c|c|}
\hline Features and characteristics & Cases $(\%) \mathrm{N}=305$ & Control (\%) $\mathbf{N}=305$ & OR & $95 \% \mathrm{CI}$ & P trend \\
\hline Average size & $1.62 \pm 0.07$ & $1.62 \pm 0.06$ & & & 0.7 \\
\hline Average weight & $76.42 \pm 14.03$ & $72.69 \pm 13.26$ & & & 0.001 \\
\hline Average BMI & $29.06 \pm 5.12$ & $27.53 \pm 4.56$ & & & 0.0001 \\
\hline \multicolumn{5}{|l|}{ Distribution of BMI } & \multirow{4}{*}{0.0001} \\
\hline Normal weight & $72(23.7)$ & $118(39)$ & & 1 & \\
\hline Overweight & $119(39)$ & $109(35.7)$ & 1.78 & $1.20-2.64$ & \\
\hline Obese & $114 \quad(37.3)$ & $78(25.6)$ & 2.39 & $1.58-3.61$ & \\
\hline \multicolumn{5}{|c|}{ Waist circumference distribution TT } & \multirow{4}{*}{0.02} \\
\hline $\mathrm{WC}<80 \mathrm{~cm}$ & $27 \quad(8.9)$ & $43(14.1)$ & & 1 & \\
\hline $80<\mathrm{WC}<88 \mathrm{~cm}$ & $38(12.5)$ & $53(17.4)$ & 1.14 & $0.60-2.15$ & \\
\hline $\mathrm{WC} \geq 88 \mathrm{~cm}$ & $240 \quad(78.7)$ & $209(68.5)$ & 1.82 & $1.09-3.06$ & \\
\hline \multicolumn{5}{|c|}{ Waist to hip ratio distribution RTH } & \multirow{3}{*}{0.001} \\
\hline WHR $<0.85$ & $105 \quad(34.4)$ & $144(47.2)$ & & 1 & \\
\hline WHR $\geq 0.85$ & $200 \quad(65.6)$ & $161(52.8)$ & 1.70 & $1.20-2.36$ & \\
\hline
\end{tabular}

Table 4: Life-time distribution of silhouettes among breast cancer cases and controls.

\begin{tabular}{|c|c|c|c|c|c|}
\hline & Cases (\%) N= 305 & Control (\%) $\mathbf{N}=305$ & OR & $95 \% \mathrm{CI}$ & P trend \\
\hline \multicolumn{5}{|c|}{ Body image at age 10} & \multirow{4}{*}{0.03} \\
\hline Lean silhouette & $47(15.4)$ & $63(20.7)$ & & 1 & \\
\hline Medium silhouette & $79(25.9)$ & $92(30.2)$ & 1.15 & $0.71-1.86$ & \\
\hline Large silhouette & $179(58.7)$ & $150(49.2)$ & 1.60 & $1.03-2.47$ & \\
\hline \multicolumn{5}{|c|}{ Body image at age 20} & \multirow{4}{*}{0.17} \\
\hline Lean silhouette & $53(17.4)$ & $61(20.0)$ & & 1 & \\
\hline Medium silhouette & $65(21.3)$ & $84(27.5)$ & 0.89 & $0.54-1.45$ & \\
\hline Large silhouette & $187(61.3)$ & $160(52.5)$ & 1.34 & $0.88-2.05$ & \\
\hline \multicolumn{5}{|c|}{ Body image at age 30} & \multirow{4}{*}{0.30} \\
\hline Lean silhouette & $20(6.6)$ & $21(6.9)$ & & 1 & \\
\hline Medium silhouette & $37(12.2)$ & $57(18.8)$ & 0.68 & $0.32-1.42$ & \\
\hline Large silhouette & $247(81.2)$ & $226(74.3)$ & 1.14 & $0.60-2.17$ & \\
\hline \multicolumn{5}{|c|}{ Body image at age 40} & \multirow{4}{*}{0.03} \\
\hline Lean silhouette & $10(3.5)$ & $7(2.4)$ & & 1 & \\
\hline Medium silhouette & $21(7.4)$ & $47(16.4)$ & 0.31 & $0.10-0.93$ & \\
\hline Large silhouette & $251(89.0)$ & $233(81.2)$ & 0.75 & $0.28-2.01$ & \\
\hline
\end{tabular}

Table 5: Associations between physical activity and breast cancer risk in cases and controls.

\begin{tabular}{|c|c|c|c|c|c|}
\hline & Cases (\%) N= 305 & Control (\%) $\mathbf{N}=305$ & OR & $95 \% \mathrm{CI}$ & P trend \\
\hline \multicolumn{5}{|l|}{ High intensity work } & \multirow{3}{*}{0.05} \\
\hline No & $99(32.5)$ & $122(40.0)$ & & 1 & \\
\hline Yes & $206(67.5)$ & $183(60.0)$ & 1.38 & $0.99-1.93$ & \\
\hline Moderate work intensity & & & & & 0.61 \\
\hline
\end{tabular}




\begin{tabular}{|c|c|c|c|c|c|}
\hline & Cases (\%) N= 305 & Control (\%) N= 305 & OR & $95 \%$ CI & $P$ trend \\
\hline No & $33(10.8)$ & $37(12.1)$ & & 1 & \\
\hline Yes & $272(89.2)$ & $268(87.9)$ & 1.13 & $0.69-1.87$ & \\
\hline \multicolumn{5}{|c|}{ Walking } & \multirow{3}{*}{0.40} \\
\hline No & $61(20.0)$ & $53(17.4)$ & & 1 & \\
\hline Yes & $244(80.0)$ & $252(82.6)$ & 0.84 & $0.55-1.26$ & \\
\hline \multicolumn{5}{|c|}{ High intensity sport } & \multirow{3}{*}{0.21} \\
\hline No & $301(98.7)$ & $304(99.7)$ & & 1 & \\
\hline Yes & $4(1.3)$ & $1(0.3)$ & 4.04 & $0.44-36.35$ & \\
\hline \multicolumn{5}{|c|}{ Moderate intensity sport } & \multirow{3}{*}{0.77} \\
\hline No & $280(91.8)$ & $278(91.1)$ & & 1 & \\
\hline Yes & $25(8.2)$ & $27(8.9)$ & 0.91 & $0.52-1.62$ & \\
\hline
\end{tabular}

Table 6: Associations between lifetime physical activity and breast cancer risk in cases and controls.

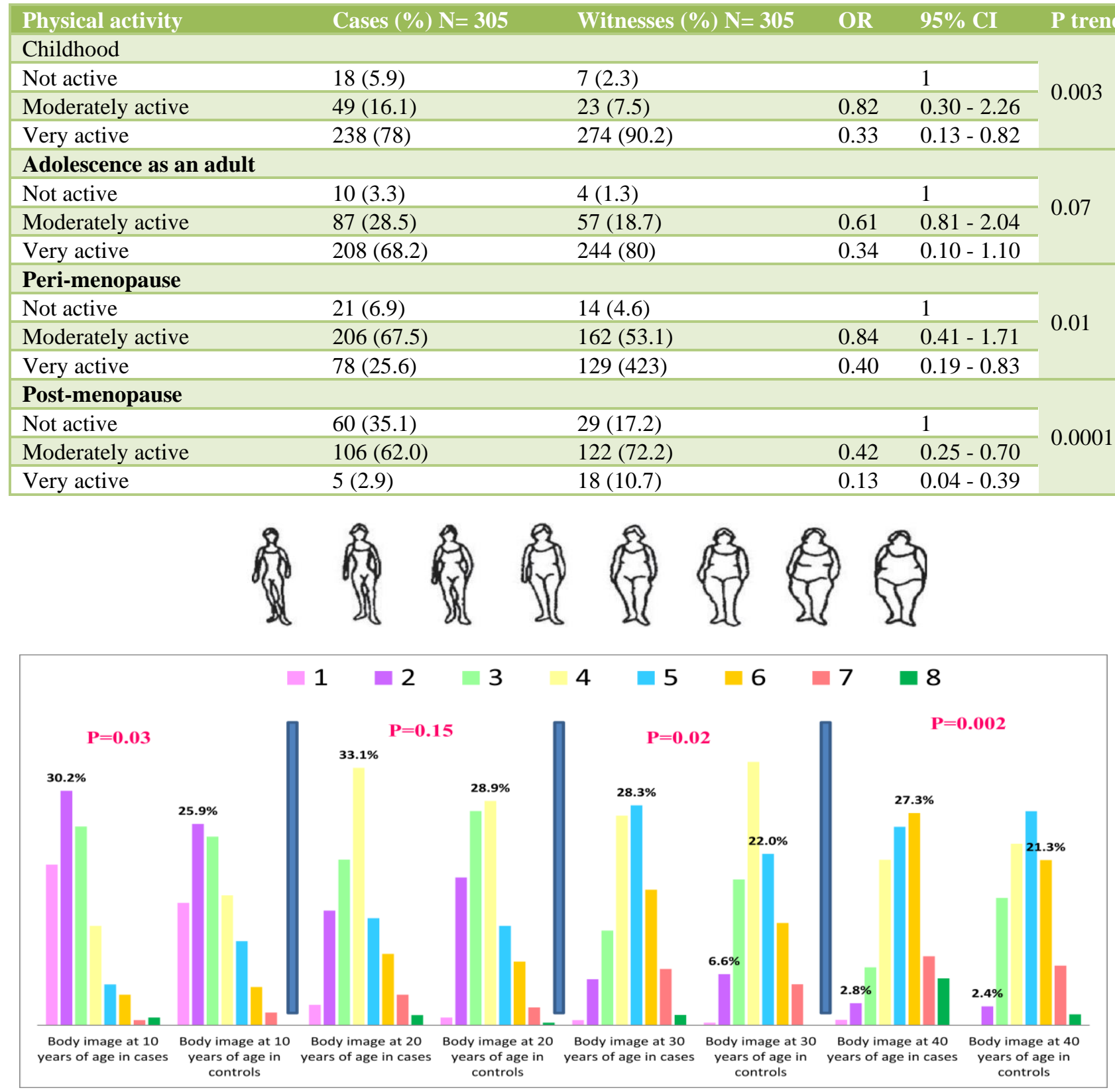

Figure 2: Distribution of body contour frequency at different ages among cases and controls. 
According to the results, there is an increase in body size over the course of a lifetime. At the age of 10, the leanest figure is the vast majority, while at the age of 40 more than $89 \%$ of women are at the tallest figure. A significant positive association has been established between the evolution of women's corpulence and the risk of developing breast cancer. This risk was estimated at 1.60 for women with a large figure compared to women with a lean figure $(\mathrm{OR}=1.60 ; 95 \% \mathrm{CI}$ : $1.03-2.47$; $\mathrm{P}$ trend $=$ $0.03)$. On the other hand, no association has been found between silhouettes at the age of 20 , at the age of 30 , and the risk of breast cancer. However, at age 40 , the average body shape relative to the lean body was associated with a decreased risk of breast cancer $(\mathrm{OR}=0.31 ; 95 \% \mathrm{CI}$ : $0.10-0.93 ; \mathrm{P}$ trend $=0.03$ ).

\section{Physical activity}

The results regarding the association between physical activity and breast cancer risk are presented in Table 5 .

In our study, the practice of high-intensity labor was higher in patients with $67.5 \%$ versus $60 \%$ in controls (OR $=1.38 ; 95 \%$ CI: $0.99-1.93 ; \mathrm{P}$ trend $=0.05)$. Moderate intensity labour is performed by $89.2 \%$ of patients vs. $87.9 \%$ of controls $(\mathrm{OR}=1.13 ; 95 \% \mathrm{CI}: 0.69-1.87 ; \mathrm{P}$ trend $=0.61$ ).

Concerning the practice of sports activities, $80 \%$ of cases walk versus $82.6 \%$ of controls $(\mathrm{OR}=0.84 ; 95 \% \mathrm{CI}$ : 0.55 - 1.26; $\mathrm{P}$ trend $=0.40)$. The practice of medium-intensity or high-intensity sports activity is low in both cases and controls, with respectively $(8.2 \%$ of cases versus 8.9 of controls with $\mathrm{OR}=0.91 ; 95 \% \mathrm{CI}: 0.52-1.62 ; P$ trend $=$ $0.77)$ and $(1.3 \%$ of cases versus 0.3 of controls with $\mathrm{OR}=4.04$; $95 \% \mathrm{CI}: 0.44-36.35$; $\mathrm{P}$ trend $=0.21$ ). Thus, no association was found between high-intensity or moderate intensity work, medium-intensity or highintensity sports activity and breast cancer risk.

The results regarding the association between lifetime physical activity and breast cancer risk are presented in Table 6.

The results show that physical activity decreases with age; in childhood and adolescence women are more active while in post-menopause women become moderately active. $78 \%$ of patients are very active during childhood vs. $90.2 \%$ of controls $(\mathrm{OR}=0.33 ; 95 \% \mathrm{CI}$ : $0.13-0.82 ; \mathrm{P}$ trend $=0.003)$. In adulthood, $68.2 \%$ of cases vs. $80 \%$ of controls are active $(\mathrm{OR}=0.34 ; 95 \% \mathrm{CI}$ : $0.10-1.10 ; \mathrm{P}$ trend $=0.07)$. In peri-menopause, only $25.6 \%$ of patients versus $42.3 \%$ of controls are active $(\mathrm{OR}=0.40 ; 95 \%$ CI: $0.19-0.83 ; \mathrm{P}$ trend $=0.01)$. In postmenopausal women, only 5 patients $(2.9 \%)$ reported high activity versus 18 controls $(10.7 \%)(\mathrm{OR}=0.13 ; 95 \%$ CI: $0.04-0.39 ; \mathrm{P}$ trend $=0.0001)$ and $62 \%$ of cases versus 72.2 of controls reported moderate activity with $\mathrm{OR}=0.40 ; 95 \% \mathrm{CI}: 0.25-0.70 ; \mathrm{P}$ trend $=0.0001$. Indeed, being very active in childhood, peri-menopause and post-menopause seems to be a protective factor against the occurrence of breast cancer.

\section{DISCUSSION}

Over the past two decades, many surveys have examined the possible role of lifestyle factors, smoking, physical inactivity, alcohol consumption and obesity in the development of breast cancer. The objective of our casecontrol study is to describe and analyze the association between these factors and the risk of breast cancer in our Moroccan population.

\section{Age, menopausal status and family history of cancer}

Age is the most important risk factor for breast cancer; the average age of our patients is $50.43 \pm 11.21$. $56.1 \%$ of them are menopausal versus $55.4 \%$ of controls. No association was found between menopausal status and breast cancer risk $(\mathrm{OR}=1.05 ; 95 \% \mathrm{CI}$ : $0.75-1.47$; $\mathrm{P}$ trend $=0.56)$.

Family history of breast cancer has been reported as one of the most important risk factors for breast cancer. ${ }^{1,4,12}$ The study confirms the important role of family history of breast cancer, which increases the risk in women with breast cancer $(\mathrm{OR}=5.73 ; 95 \% \mathrm{CI}: 3.07-10.67$; $\mathrm{P}$ trend $=$ $0.0001)$. These results are relatively consistent with those of or who found a 3.5-fold increased risk of breast cancer in women aged 49 years. ${ }^{13-16}$ Women at hereditary risk of breast cancer are a special population. On the one hand, their risk of breast cancer is extremely high. On the other hand, the young age of onset of their cancer is probably due to specific abnormalities in breast carcinogenesis, which means that the associated risk factors may differ from those identified in a sporadic context.

\section{Toxic habits}

In the study, smoking is weakly found in the population; it does not seem to have any effect on the overall risk of developing breast cancer. This result is consistent with a collaborative analysis of 53 epidemiological studies and case-control studies. ${ }^{5,14,17}$ However, other authors have found an increased relative risk of breast cancer for women who actively smoke. ${ }^{18-20}$

In addition, the study also indicates that alcohol consumption is a significant risk factor for breast cancer among women who drink alcohol compared to those who do not $(\mathrm{OR}=3.76 ; 95 \% \mathrm{CI}$ : 1.37 - 10.26; $\mathrm{P}$ trend $=$ 0.0001 ). This finding has been noted in numerous studies that have shown that alcohol consumption is a moderate but consistent risk factor for breast cancer. Women who reported drinking alcohol increased their relative risk of breast cancer compared to those who reported no alcohol consumption (for example, OR $=1.32$, 95\% CI 1.19-1.45 for a consumption of 0.35 to $44 \mathrm{~g}$ per day of alcohol and $\mathrm{OR}=1.46,95 \%$ CI 1.33 to 1.61 for a daily intake $\geq 45 \mathrm{~g}$, $\mathrm{P}$ trend <0.00001). ${ }^{4}$ Alcohol influences estrogen and 
folate metabolism, gene regulation and mutagenesis induction.

\section{Anthropometric measurements}

The results confirm that overweight is associated with an increased incidence of breast cancer. The risk of developing breast cancer is estimated at 1.78 in overweight women and 2.39 in obese women compared to those of normal weight. This positive association of breast cancer risk with the BMI index $\geq 30 \mathrm{~kg} / \mathrm{m}^{2}$ found in the study $(\mathrm{OR}=2.39)$ is higher than that reported by. ${ }^{13,21}$ In the literature, the results for BMI are mixed. ${ }^{22}$ $\mathrm{Hu}$ et al reported a decreased risk of breast cancer with $\mathrm{BMI}$ in non-menopausal women $(\mathrm{RR}=0.45 ; 95 \% \mathrm{CI}=$ $0.22-0.92$ for a BMI $\geq 23$ versus $\left.<21 \mathrm{~kg} / \mathrm{m}^{2}\right)$ and an increased risk in postmenopausal women $(\mathrm{OR}=1.98$; $95 \% \mathrm{CI}=0.86-4.55$ for a $\mathrm{BMI} \geq 24$ versus $<21.5$ $\left.\mathrm{kg} / \mathrm{m}^{2}\right) .{ }^{18}$

In the study, the risk of developing breast cancer is estimated at 1.82 in women with a WC greater than 88 $\mathrm{cm}$ and 1.70 in women with a WHR greater than 0.85 $(\mathrm{OR}=1.82 ; 95 \% \mathrm{CI}: 1.09-3.06 ; \mathrm{P}$ trend $=0.02)$ and $(\mathrm{OR}=1.70 ; 95 \% \mathrm{CI}: 1.20-2.36 ; \mathrm{P}$ trend $=0.001)$.

The results of reducing breast cancer risk before and after menopause, with an increase in WC, HC and WHR, are inconsistent in most previous studies conducted in high resource countries. ${ }^{23-27}$ More recently, a study conducted in a multi-ethnic American population showed insignificant inverse associations between WHR and WC in women and breast cancer risk, $(\mathrm{OR}=0.71,95 \% \mathrm{CI}=$ $0.46-1.11$, for $\mathrm{WHR}>0.85$ versus $\mathrm{WHR} \leq 0.77$; and $\mathrm{OR}=0.74,95 \% \mathrm{CI}=0.47-1.17$ for $\mathrm{WC}>98 \mathrm{~cm}$ versus $\mathrm{WC} \leq 78.7 \mathrm{~cm}) .{ }^{28}$ Overall, these results suggest that anthropometric factors may have different associations with breast cancer risk in women, perhaps due to ethnic variations in the distribution of body fat.

\section{Evolution of corpulence over the life course}

In order to clarify the relationship between adiposity and breast cancer, it was also necessary to take into account the history of corpulence by using Sorensen's silhouettes at different periods of life and its variations over time. To date, few studies have examined the relationship between body shape in young children and breast cancer risk in Moroccan women.

The analysis of our results showed a significant positive association between the evolution of women's corpulence and the risk of developing breast cancer. In the literature, studies have shown that the wide body shape relative to the constantly lean body shape is associated with a decreased risk of breast cancer $(P$ trend $=0.01){ }^{28,29}$ However, several other studies conducted primarily in Western countries have shown that an increase in body fat (BMI, weight) in young people was associated with a lower risk of breast cancer in premenopausal women and postmenopausal women. ${ }^{29-34}$ The results highlight that at pre-adolescence, the risk of breast cancer is estimated at 1.60 for women with a large figure compared to women with a small figure $(\mathrm{P}$ trend $=0.03)$. In contrast, at age 40 , the average body shape relative to the lean body shape was associated with a decreased risk of breast cancer ( $P$ trend $=0.03$ ).

The biological mechanisms linking anthropometric parameters and breast cancer risk in postmenopausal women have been clearly established. It has long been known that overweight and obese adolescents have an earlier menarche than normal weight girls; early menarche is associated with a positive risk of breast cancer. $^{35-37}$ After cessation of ovarian activity, sex steroids, especially estrogens, remain synthesized mainly in adipose tissue. Obesity is then positively correlated with increased plasma testosterone and estradiol concentrations. Obesity also leads to insulin resistance, hyperinsulinemia and increased levels of bioavailable IGFI, an insulin-like growth factor involved in breast tissue development and tumour promotion. ${ }^{38}$ This also results in a decrease in SHBG concentration, resulting in an overall increase in plasma levels of androgens and free estrogens. ${ }^{39-43}$ Obesity also induces low-grade chronic inflammation leading to increased local and systemic cytokine levels.

These factors in turn can affect mitosis, apoptosis, cell senescence and angiogenesis [39]. Together, these hormonal and metabolic effects could facilitate tumorpromoting effects associated with a body shape of increasing shape throughout life and breast cancer risk. With respect to possible protective biological mechanisms, it has been postulated that, in premenopausal women, estradiol and progesterone levels are reduced in anovulatory cycles that occur more frequently in obese women than in thin women. ${ }^{44}$

These two hormonal effects may reduce hormonedependent tumour growth in overweight and/or obese women, which partly explains the negative association between current anthropometric measurements (BMI, TT, and THR) and breast cancer risk observed in nonmenopausal women.

\section{Physical activity}

Scientific evidence indicates that physical inactivity is the main known and modifiable health risk factor. ${ }^{45}$ The study found that the risk of breast cancer was lower in highly active women compared to those who are inactive, regardless of menopausal status. This finding is consistent with the study by Kamarudin et al who found that breast cancer risk was significantly higher among inactive women $(\mathrm{OR}=3.489)$ than among those who exercised regularly. ${ }^{46}$ In addition, data from the study by Dallal et al showed a $20 \%$ reduction in the risk of invasive breast cancer in women with regular physical activity $>5$ hours/week. ${ }^{47}$ 
The role of physical activity is linked to various mechanisms of action. In the short term, muscle contraction involves energy and hormonal metabolism with consumption of energy substrates and increased insulin sensitivity, and in the long term physical activity modifies body composition, reducing fat mass and increasing muscle mass, a real generator of energy expenditure, necessary to limit the supply of energy substrates stimulating carcinogenesis, improve insulin sensitivity, modulate the ratio of adipokines, leptin and adiponectin, improve cellular immunity and block cell pathways favourable to cell proliferation and angiogenesis. ${ }^{48}$

\section{CONCLUSION}

The results of this study provide additional evidence that lifestyle factors (obesity, physical inactivity, smoking, alcohol consumption) and a family history of breast cancer are associated with a high risk of breast cancer. This should encourage women to change their behaviour, especially with regard to toxic habits and physical inactivity that may increase their risk of breast cancer. It is also recommended that women maintain a normal weight and avoid increasing body weight throughout life.

\section{Funding: No funding sources}

Conflict of interest: None declared

Ethical approval: The study was approved by the Institutional Ethics Committee

\section{REFERENCES}

1. Antoniou AC, Pharoah PDP, Narod S, Risch HA, Eyfjord JE, Hopper JL. Breast and ovarian cancer risks to carriers of the BRCA1 5382insC and 185delAG and BRCA2 6174delT mutations: a combined analysis of 22 population based studies. J Med Genetics. 2005;42(7):602-3.

2. Dumitrescu RG, Cotarla I. Understanding breast cancer risk where do we stand in 2005? J Cellular Molecular Med. 2005;9(1):208-1.

3. Colditz GA, Atwood KA, Emmons K, Monson RR, Willett WC, Trichopoulos D, Hunter DJ. Harvard report on cancer prevention. Harvard Cancer Risk Index. 2000;11(6):477-88.

4. Hulka BS, Moorman PG. Breast cancer: hormones and other risk factors. Mauritas. 2001;38:103-16.

5. Collaborative Group on Hormonal Factors in Breast Cancer. Alcohol, tobacco and breast cancer collaborative reanalysis of individual data from 53 epidemiological studies, including 58515 women with breast cancer and 95067 women without the disease. Br J Cancer 2002; 87:1234-45.

6. Stasiolek D, Kwasniewska M, Drygas W. Raksutka selected risk factor, primary prevention. Przeglad Lekarski. 2002;59:26-30.

7. Nkondjock A, Shatenstein B, Ghadirian P. A casecontrol study of breast cancer and dietary intake of individual fatty acids and antioxidants in Montreal, Canada. Breast. 2003;12:128-35.

8. McTiernan. Behavioral risk factors in breast cancer: can risk be modified? The Oncologist. 2003;8:42634.

9. Sorensen TI, Stunkard AJ, Teasdale TW, Higgins MW. The accuracy of reports of weight: children's recall of their parents' weights 15 years earlier. Int $\mathbf{J}$ Obes. 1983;7:115-22.

10. Casey VA, Dwyer JT, Coleman KA, Krall EA, Gardner J, Valadian I. Clarification of the recall of middle-aged participants in a longitudinal study of their body size and maturation indices earlier in life. Ann Human Biol. 1991;18(2):155-66.

11. Must A, Phillips SM, Naumova EN, Blum M, Harris S, Hughes D, Rand B. Reminder of menstrual history and body size: after 30 years, to what extent do women remember? Am $\mathrm{J}$ Epidemiol. 2002;155(7):672-9.

12. Claus EB, Schildkraut JM, Thompson LD. The genetic attributable risk of breast cancer and ovarian cancer. Cancer. 1996;77:2318-24.

13. Reinier KS, Vacek PM, Geller BM. Risk factors for breast carcinoma in situ versus invasive breast cancer in a prospective study of pre- and post-menopausal women. Breast Cancer Res Treat. 2007;103:343-8.

14. Hirose K, Tajima K, Hamajima N. A large-scale, hospital-based case-control study of risk factors of breast cancer according to menopausal status. Jpn $\mathbf{J}$ Cancer Res. 1995;86:146-54.

15. Hirose K, Tajima K, Hamajima N. Association of family history and other risk factors with breast cancer risk among Japanese premenopausal and postmenopausal women. Cancer Causes Control. 2001;12:349-58.

16. Minami Y, Ohuchi N, Fukao A. Risk factors for breast cancer: A case-control study of screendetected breast cancer Miyagi Prefecture, Japan. Breast Cancer Res Treat. 1997;44:225-33.

17. Lissowska J, Brinton LA, Zatonski W. Mannosebinding lectin-2 genetic variation and stomach cancer risk. Int J Cancer. 2006;119:1961-9.

18. Hu YH, Nagata C, Shimizu H. Association of body mass index, physical activity and reproductive histories with breast cancer: a case-control study in Gifu, Japan. Breast Cancer Res Treat. 1997;43:6572.

19. Khuder SA, Mutgi AB, Nugent S. Smoking and breast cancer: a meta-analysis. Rev Environ Health. 2001;16:253-61.

20. Katsouyanni K, Trichopoulou A, Stuver S, Ethanol and breast cancer: an association may be both confounded and causal. Int J Cancer. 1994;58:35661.

21. Favero A, Parpinel M, Franceschi S. Diet and risk of breast cancer: major findings from an Italian casecontrol study. Biomed Pharmacother. 1998;52:10915.

22. Carmichel AR, Bates T. Obesity and breast cancer: a review of literature. The Breast. 2004;13:85-92. 
23. Connolly BS, Barnett C, Vogt KN. A meta-analysis of published literature on waist-to-hip ratio and risk of breast cancer. Nutr Cancer. 2002;44(2):127-38.

24. Hall IJ, Newman B, Millikan RC. Body size and breast cancer risk in black women and white women: the carolina breast cancer study. Am J Epidemiol. 2000;151(8):754-64.

25. Harvie M, Hooper L, Howell AH. Central obesity and breast cancer risk: a systematic review. Obes Rev. 2003;4(3):157-73.

26. Shu XO, Jin F, Dai Q. Association of body size and fat distribution with risk of breast cancer among Chinese women. Int J Cancer. 2001;94(3):449-55.

27. Shin A, Matthews CE, Shu XO. Joint effects of body size, energy intake, and physical activity on breast cancer risk. Breast Cancer Res Treat. 2009;113(1):153-61.

28. John EM, Sangaramoorthy M, Phipps AI. Adult body size, hormone receptor status, and premenopausal breast cancer risk in a multiethnic population: the San Francisco bay area breast cancer study. Am J Epidemiol. 2011;173(2):201-16.

29. Slattery ML, Sweeney C, Edwards S. Body size, weight change, fat distribution and breast cancer risk inHispanic and non-Hispanic white women. Breast Cancer Res Treat. 2007;102(1):85-101.

30. Palmer JR, Campbell LL, Boggs DA. A prospective study of body size and breast cancer in black women. Cancer Epidemiol Biomarkers Prev. 2007;16(9):1795-802.

31. Baer HJ, Colditz GA, Rosner B. Body fatness during childhood and adolescence and incidence of breast cancer in premenopausal women: a prospective cohort study. Breast Cancer Res. 2005;7(3):314-25.

32. Baer HJ, Tworoger SS, Hankinson SE. Body fatness at young ages and risk of breast cancer throughout life. Am J Epidemiol. 2010;171(11):1183-94.

33. Berstad P, Coates RJ, Bernstein L. A case-control study of body mass index and breast cancer risk in white and African-American women. Cancer Epidemiol Biomarkers Prev. 2010;19(6):1532-44.

34. Bardia A, Vachon CM, Olson JE. Relative weight at age 12 and risk of postmenopausal breast cancer. Cancer Epidemiol Biomarkers Prev. 2008;17(2):3748.

35. Tehard B, Saris WH, Astrup A, Martinez JA, Taylor MA, Barbe P, Oppert JM. Comparison of two physical activity questionnaires in obese subjects: the NUGENOB study. Med Sci Sports Exercise. 2005;37(9):1535-541.

36. Ahmed ML, Ong KK, Dunger DB. Childhood obesity and the time of puberty. Trends in Endocrin Metab. 2009;20(5):237-42.

37. Althuis MD, Fergenbaum JH, Closas GM, Brinton LA, Madigan MP, Sherman ME. Etiology of hormone receptor-defined breast cancer: systematic review of the literature. Cancer Epidemiol Biomarkers Prevention. 2004;13(10):1558-68.

38. Bertrand T, Chapelon FC. The E3N group. Several anthropometric measurements and breast cancer risk: results of the E3N cohort study. Int $J$ Obes. 2006;30(1):156-63.

39. Calle EE, Kaaks R. Overweight, obesity and cancer: epidemiological evidence and proposed mechanisms. Nat Rev Cancer. 2004;4(8):579-91.

40. Key TJ, Appleby PN, Reeves GK. Insulin-like growth factor 1 (IGF1), IGF binding protein 3 (IGFBP3), and breast cancer risk: pooled individual data analysis of 17 prospective studies. Lancet Oncol. 2010;11(6):530-42.

41. Key T, Appleby P, Barnes I. Endogenous sex hormones and breast cancer in postmenopausal women: reanalysis of nine prospective studies. J Natl Cancer Inst. 2002;94(8):606-16.

42. Rinaldi S, Peeters PH, Berrino F. IGF-I, IGFBP-3 and breast cancer risk in women: the European Prospective Investigation into Cancer and Nutrition (EPIC). Endocr Relat Cancer. 2006; 3(2):593-605.

43. Slattery ML, Baumgartner KB, Byers T. Genetic, anthropometric, and lifestyle factors associated with IGF-1 and IGFBP-3 levels in Hispanic and nonHispanic white women. Cancer Causes Control. 2005;16(10):1147-57.

44. Wenten M, Gilliland FD, Baumgartner K. Associations of weight, weight change, and body mass with breast cancer risk in Hispanic and nonHispanic white women. Ann Epidemiol. 2002;12(6):435-4.

45. International agency for research on cancer (IARC). IARC Handbooks of Cancer Prevention. Weight Control and Physical Activity. IARC Press: Lyon. 2002;6.

46. Kamarudin R, Shah SA, Hidayah N. Lifestyle factors and breast cancer: a case-control study in Kuala Lumpur, Malaysia. Asian Pacific J Cancer Prev. 2006;7:51-4.

47. Dallal CM, Halley J, Ross RK. Long-term recreational physical activity and risk of invasive and in situ breast cancer: the California teachers study. Arch Intern Med. 2007;167:408-15.

48. Master C. Relationship between physical activity, weight balance and breast cancer Relationship between physical activity, weight balance and breast cancer. Annals of Endocrinology. 2013;74(2):14853.

Cite this article as: Drissi $\mathrm{H}$, Imad FZ, Bendahhou K, Benider A, Radallah D, Lifestyle factors and breast cancer in a Moroccan population case-control study of the center Mohammed VI for cancer treatment.. Int J Reprod Contracept Obstet Gynecol 2019;8:3825-33. 